SITES: NEW SERIES $\cdot$ VOL 15 NO $1 \cdot 2018$

DoI: http://dx.doi.org/10.11157/sites-id338

- ARTICLE -

\title{
METAPHORS-OF-KNOWING: EXPLORING SENSE CONSCIOUSNESS THROUGH ART
}

\author{
Ruth Gibbons ${ }^{1}$
}

\begin{abstract}
Exploring people's everyday lives is central to anthropological participant observation. This article considers a different type of participant observation through art as a process of engaged exploration of the way people know the world. Working collaboratively with a variety of dyslexics in NZ and the UK, we sought to understand the dyslexia experience and what it means to be dyslexic from their perspective. Dyslexia research has a dominant focus on the neurological, abstracting experience into a neuro-self. Through the use of art we were able to refocus back onto everyday embodied experience. Through the act of making, my collaborators' work evolved into investigations of complex ways-of-knowing, revealing how dyslexia impacted the way they paid attention to and expressed their knowing of the world. I take inspiration from Hogan and Pink (2010) and Rapport and Harris (2007), who have discussed the importance of understanding specific ways of knowing. In this project, art became an exploration of how dyslexics experience and know the world around them. Considering knowing requires being able to express this knowledge in ways which are relevant to what has been reflected. This article engages with embodied knowing and worlding through the artworks created by my collaborators, offering a new way to explore and represent people's lived experiences.
\end{abstract}

Keywords: dyslexia; knowing; collaboration; art

\section{INTRODUCTION}

In my brain, I am seeing a picture of what you're doing as a tidal wave, with everything dyslexic as the water, and you're being surrounded. We're on the sideline in the distance going, 'let it take you, just go with it. Let it take you'! (Amanda) 
As Amanda finished the gesture of a crashing wave, laughter exploded around the table and everyone agreed that being surrounded and overtaken by dyslexic experiences summed up my role as researcher. Through the physicality of making art, I was being drawn into their experiences.

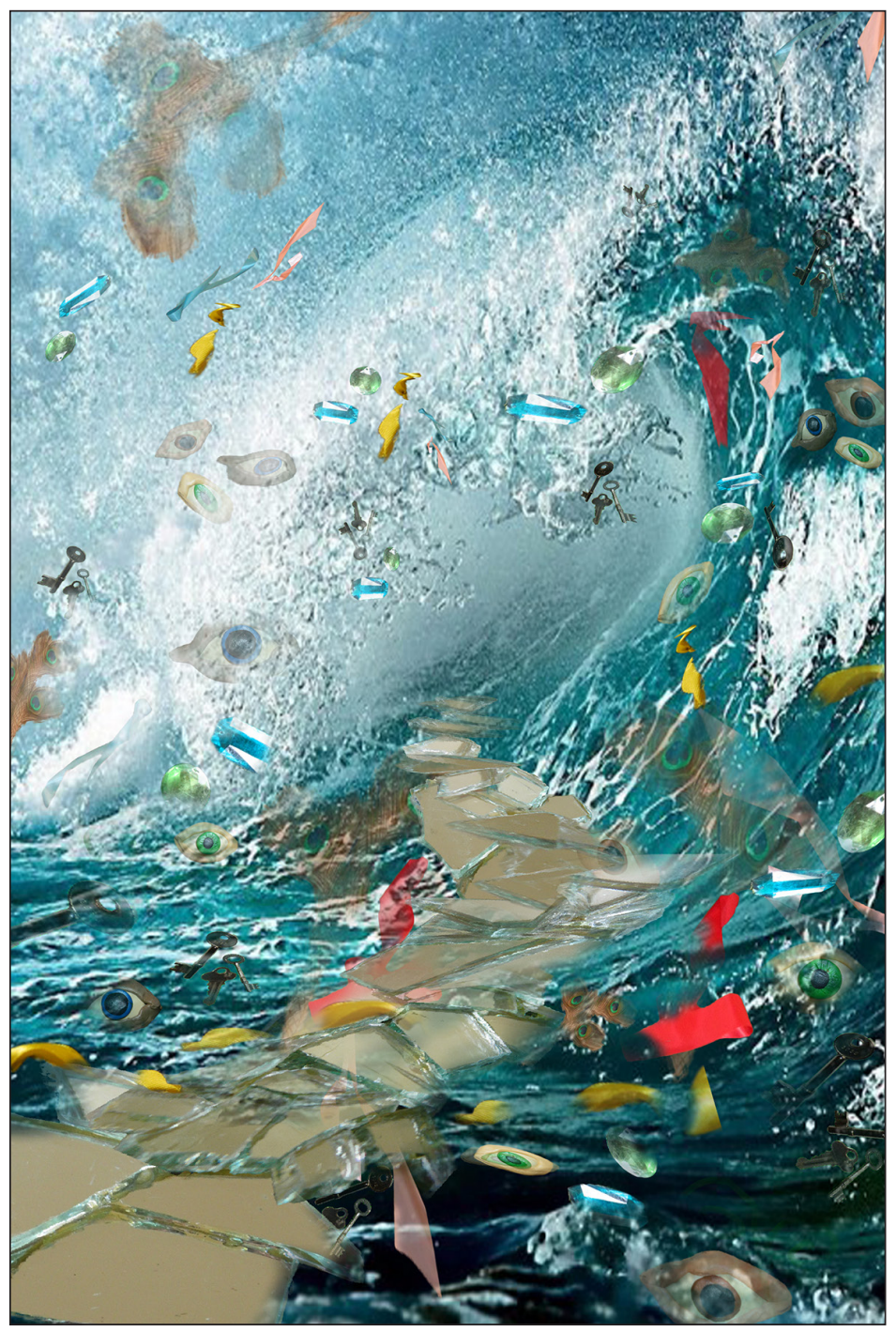

Figure 1. 'Just Go With It' (Digital Collage) 
Being part of a community and experiencing a type of apprenticeship is part of the anthropological project, as we learn people's ways of moving through the world. My fieldwork used art as a shared space of making which revealed rituals and practices of dyslexic experience. In this article, I look at these ways of 'knowing' through physical making (Ingold 2013), language and embodied experience. Pickering (2008) has suggested that art is a place that is uniquely suited to capturing experience, as it sounds 'an insistence on the significance of listening to others and attending to what is relatively distinctive in their way of knowing the world for it is only by doing this that we can glean any sense of what is involved in their subjectivities, self-formation, life histories and participation in social and cultural identities' (p.23). I discuss these symbolic representations through words, sounds, movement and art and how they reveal potential in collaborative research, provide different ways of entering the field, expand the field for ethnographic research and create particular forms of disseminating knowledge ${ }^{2}$. My chosen field site was with people who are dyslexic. In the existing literature the dominant voice about dyslexia (and what makes a person dyslexic) problematises access to language - or, more recently, also focuses on giftedness, with visual processing strengths given as a reason for problems with language (Eide and Eide 2011; Shaywitz 2008). In my research I found contradictions, complexities and layers of information threaded through the different artistic methods and mediums we used. I sought to balance these with academic requirements, my ethical responsibilities to my collaborators (I discuss the use of this term in more detail shortly) and the limits to how I could explore and 'write up' my research. These mediums represented different ways of communicating knowledge and helped my collaborators express their own voices.

WHAT'S IN A NAME: DYSLEXIA

Words, and the different forms they take, are central to this project - not least of all, the term 'dyslexia', which led me to my fieldwork. I include here a brief explanation of the word, but due to the constraints of this article I cannot do so in detail (see Gibbons 2016). Words are placed at the centre of the dyslexia debate as they are used to define a core disability; words are probably the first thing that came to your mind when you read 'dyslexia. However, dyslexia is a contested term. This is, in part, because it is problematically situated within Western medical, psychological and educational discourses. Dyslexia has not been investigated through long-term ethnographic research, which would bring a much-needed alternative perspective to challenge these dominant discourses. Dyslexia, as a diagnosis, was first used over 100 years ago to describe a child who could not read despite having all the advantages of a 'good education' 
(Shaywitz 2008). The term draws on the Greek 'lexis', meaning to speak and read, and adds the prefix 'dys', meaning difficult, combining them to mean difficulty with words, or bad words. The term dyslexia was coined in Europe and has since been attached to other, similar issues relating to problems with words across a variety of different cultures and languages (Smith, Everatt, and Salter 2004). The word is now being used to diagnose persons ${ }^{3}$ throughout the world, though no biological/medical cause for dyslexia has been identified (Elliot and Grigorenko, 2014). Even MRIs, which are frequently used to show differences in reading abilities between dyslexics and non-dyslexics, show different responses depending on the cultural background of the study participants (Siok, Niu, Jin, Perfetti, and Tan 2008).

Elliot and Grigorenko (2014), in a recent review of dyslexia research, describe the word as ambiguous and of limited value. Different countries have their own definitions for dyslexia and there is no 'cure', although in some countries a diagnosis of dyslexia can provide access to support systems. This has resulted in debates across the dyslexia research communities, remedial industries and the public sphere. Elliot and Grigorenko suggest that 'dyslexia' is meaningless as a diagnostic category. They relate this to the inconsistent approaches to diagnosis (there is no globally recognised single test or set of tests which definitively define dyslexia) and state that debates about what is 'faulty' - whether it is caused by defects in the brain, vision or auditory processing - impact the types of remedial treatment available. They argue that, rather than labelling large numbers of people as disabled, pedagogical methods and schooling should be reformed ${ }^{4}$. However, their review showed that many prominent researchers remain embedded in the medical discourse and do not focus on what dyslexics say about themselves.

The differing definitions of dyslexia used by researchers also compromise the validity of the term. Definitions range from describing it as 'a spectrum of learning difficulties evident when accurate and/or fluent reading and writing skills, particularly phonological awareness, develop incompletely or with difficulty' (Dymock and Nicholson 2012, 14) to brains being deficient or flawed (Bishop 2007; Davis and Braun 2010; Raphael, Salovesh, and Laclave 2001). There is little to no recognition of the variability in cultural expectations about language development and use, or the prioritisation of educational and remedial institutions' approaches to language learning, which still emphasise phonics and spelling memorisation. Author and dyslexic Sally Gardner (2014) challenged these perspectives, explaining: 'I am absolutely sick to death of being told how we should learn and what we should do. It's just - what are we doing? What are we doing? And why do we let it happen, is more to the point. 
There's enough of us now to just stand up and say no' (Gardner in Varvardies and Bielecki 2014).

The initial reasons people seek help and also the key identifiers of dyslexia remain problems with reading, spelling and writing, although in different countries additional 'symptoms' have been added and others subtracted. For example, New Zealand considers the inability to read music as a marker of dyslexia, but it is the only country to do so (Elliott, personal communication, 2015).

Dyslexia research focuses predominately on deficits, and those deficits are attributed to different causes, including phonological problems (Chevin 2009), difficulty interpreting word shapes (Koenig and Wolff 1991) and memory issues (Rosen 2006). Much of this research is undertaken by non-dyslexics, who then study and analyse the dyslexics' experiences. Therefore, the word 'dyslexia' contains within it a variety of interpretations of people's embodied experiences. These different definitions include defining dyslexic brains/minds as an individual's 'problem' rather than a common human variation found in approximately one in five people. The recognition of dyslexia has resulted in several countries, such as the United Kingdom and the United States, using legislation to define dyslexia as a disability - more recently terms such as 'neuro-diversity' have become a way to push back against the label disability. The 'neuro-self' is becoming more dominant in dyslexia discourses, with embodied experience being ignored in favour of a focus on the brain, which is then fused with the mind. Fernando Vidal and Francisco Ortega (2017) suggest that there are consequences to this focus:

'the neuro', the complex of theories, practices, and institutions that supports cerebral selfhood, thereby sacrific[es] the messy 'phenomenological, embodied, and affective dimension[s] of human experience'. (p. 203)

The current, deficit-focused research using MRIs medicalises people's lived, everyday experiences, recently resulting in the Yale Centre for Dyslexia and Creativity's trial of medication to 'fix' dyslexia (Shaywitz et al. 2015) - even though, as stated above, there is no known etiology ${ }^{5}$. The trials failed and led to debates throughout the dyslexia community about the appropriateness of medical treatment (Eide 2016), especially as the 'giftedness discourse' around dyslexia often suggests that deficits in reading and writing are compensated for by gifts in other areas (Eide and Eide 2011). I have yet to find research about the socio-cultural 'embodied cognition' (Shapiro 2014) of dyslexia, as the emphasis in dyslexia research is predominately on brain development, with neurological 
studies valued as giving an objective window onto a hidden world. Anthropology can challenge dominant discourses about dyslexia and critique how they universalise cultural expectations about knowledge acquisition.

Unfortunately, existing studies of word acquisition within dyslexia research create a self-perpetuating discourse about the importance of reading and writing. Using a visual/sensory anthropological approach to the everyday experiences of people with dyslexia revealed more complex issues around language than the existing literature shows. Through art (Gibbons, 2016), I found that problems with reading and writing were not simply about difficulties in text acquisition or phonetic awareness (Chevin 2009; Dehane et al. 2014) but rather were about what words contain. For dyslexics in this study, words were not simply associated with deficit, but were also 'holders' of deep sensory information. As Amanda explained, when reading a book, 'as you walk alongside the characters, you're even smelling the grass as it crushes under your feet. You have to be quiet [because] you don't want to be noticed; being noticed would disrupt it'. Amanda's comment complicates conventional definitions of dyslexia as difficulty with reading; she suggests instead an embodied and multisensory way of reading.

Words, whilst central to the problems associated with dyslexia in the existing literature, were redefined by my key collaborators in the study who, like Amanda, saw words as sensorially dense holders of information. My key collaborators were concerned that they had not been taught how to access this vital knowledge and had to work it out for themselves. They explained that this was not what they were taught words 'do'; they were taught that words were bounded, distinct objects that needed to be memorised and attained. Elise explained, 'there was this cue card of a tree they were teaching me to read with; cartoon picture on one side, word on the other. Now every time I read the word "tree", that picture pops into my head and it mucks up the whole picture the book is creating. Conventional dyslexia research approaches do not create space to discover and explore these experiences; ethnography can.

Talking with me in 2013, Naomi Folb, a researcher with dyslexia, challenged the lack of insider research and the silencing of dyslexic voices. She expressed frustration with existing research methods, and questioned the dominance of non-dyslexic voices at conferences and in research articles, asking 'why, at a conference on dyslexia, were there no dyslexic speakers?' (personal communication, 2013) A participant in this study, Anne, reinforced this point, explaining that the current research paradigms result in 'our voices not [being] heard'. Through participant observation, anthropology has the potential to bring these voices 
forward, as it seeks to understand people's ways of 'making their world'. Using a culturally embedded approach means that we do not instantly problematise differences or deficits, but rather seek to understand persons as active participants by being-in-the-world alongside them. Through documenting these cultural spaces, these unheard voices can be brought into the dyslexia debate.

\section{A visual/sensory approach to dyslexia}

I began by seeking to understand how people with dyslexia themselves used the term dyslexia, rather than focusing on the medical (Chevin 2009; Price et al. 1998), educational (Caroll and Iles 2006; Rowan 2010), social disability (Watson 2011) and psychological approaches (Shaywitz 2008). Therefore, it was important to move away from the definitions each of those approaches use, as they rely on shared findings that reproduce the mainstream dyslexia discourse. For example, functional magnetic resonance imaging (fMRI) is commonly used within medical research on dyslexia, and these findings are drawn on in psychology and when developing educational remedial approaches to dyslexia. This medical imaging can miss

the objectness of the scan [which] is not only illusionary but potentially damaging... the potential of deletion of compounding social features... through the starkness of the final images, must consequently remain a real concern. (Edwards, Harvey, and Wade 2010, 18)

The brain has occupied a dominant place within dyslexia research; a place where the brain becomes conflated with the mind and the mind-body dichotomy reigns (as can be seen in the review of research by Elliot and Grigorenko 2014).

Within social anthropology, investigation of 'the whole' is central to our practice. When applied to this case, an anthropological approach highlights the gap in the dyslexia literature. Within dyslexia literature there is a focus on the mind with the body often becoming, at best, a piece of 'exercise equipment' (particularly within remedial literature) for correcting the problems of the brain. In the activist literature, the mind is still 'the battle ground', with emphasis placed on 'M.I.N.D.'(Material Reasoning, Interconnected reasoning, Narrative Reasoning and Dynamic reasoning) strengths (Eide and Eide 2011), meaning that those on both sides of the debate privilege, and at times conflate, the mind and brain. I shift perspective from understanding the mind to understanding embodied knowing. I draw on Buck-Morss (1992), who uses the original Greek meaning of 'the aesthetic', explaining the brain 'is not an isolable anatomical body, but part 
of a system that passes through the person and his or her (culturally specific, historically transient) environment' (p.12). This cultural, historical, embodied engagement privileges the senses as beginning and ending in the world, not as products limited to the mind. ${ }^{6}$

Inclusion of the voices of people with dyslexia was an issue I felt needed to be addressed in my own research, and I began by choosing a collaborative approach, as I am not dyslexic myself. I needed to develop a method that expanded the research to incorporate the complex voices of dyslexics, giving them some form of parity/equal voice with my own. In doing so, I looked for ways to alter the dominance of my own voice in the research.

To distinguish between knowledge from the dyslexia literature and insider embodied knowledge, my collaborators and I chose to change the appearance of the word to 'dysleXia' to distinguish between these different voices. This happened because, when I was writing up my thesis, it became confusing to read. I was using the same form of the word 'dyslexia' to represent these different types of knowledge but it was important to make a distinction between the two. My key collaborators (who came from New Zealand) chose to capitalise the ' $\mathrm{x}$ ' for two reasons: firstly because the letter can be flipped and turned upside down without changing its meaning, and secondly because ' $x$ marks the spot' (as said by one of my collaborators, Amanda). This allowed their voices, rather than the medical and psychological discourse about dyslexia, to dominate. I mention this change here as I will be using these two forms of the word in the rest of this article.

\section{Participating in research}

Collaboration was central to my research, and this is the reason I do not use the term 'participants' to describe the people I worked with. The use of the term 'collaborators' reflects my methodological approach, to which sharing in researching and representing experiences is central. My collaborators came from New Zealand and the United Kingdom, identified themselves as dyslexic and had a wide age range, from ten to sixty-five years old. This is an unusual approach in dyslexia research, as research tends to focus on specific age groups rather than across generations; it is also predominately research with children. My collaborators came from a variety of backgrounds. The adults varied from unemployed to academics, and the adolescents and children were either home-schooled or in the education system and were predominantly of European ethnicity. 
My collaborators had different opinions on what it meant to be dyslexic. They were on a continuum - from interpreting their experience as an extreme disability: 'I have a disorder; I am disabled' (Barry) - to seeing themselves as profoundly gifted: '[non-dyslexics] lead boring and unimaginative lives. They miss out on so much' (Amanda). Their awareness of 'outside' (research, academic, remedial therapy) definitions of their own personhood as dyslexic also differed. In New Zealand, the adults had not much external intervention influencing how they interpreted their experience, and as such were relatively removed from the whirlwind of academic theories of dyslexia. However, in the United Kingdom dyslexia is connected to disability legislation where support services can only be accessed through various agencies, necessitating a diagnosis of 'disability' to do so. These differences in governmental policy of dyslexia influenced how my collaborators discussed dyslexia and the language they used to do so, as shown by the quote above from Barry (who is from the United Kingdom).

As I began my research, I found the diverse voices of dysleXics to be strangely silent in the academic literature. These voices were especially missing when looking more broadly at the everyday experience of dyslexia beyond the topic of reading disability.

When I began my research I believed, as the literature stated, that words would be problematic for people who had had negative experiences of them, and as such art provided a methodology that was less 'word dominant.' I looked for a way to share the research process, while at the same time enabling people who did not want that level of involvement in the research to take part in it. Art practices provided this opportunity. Using more traditional ethnographic methods would have been challenging as there is no 'village' of dysleXics, and in New Zealand there are no support groups for adults. Many of my New Zealand collaborators did not know any dyslexics outside of their own families, and as such it was the first time they were able to explore with other people what dysleXia meant to them.

Working collaboratively with dysleXics, and using art as a way to share in both exploring and representing the experience of dysleXia, altered the way I practised anthropology. For my fieldwork, I invited people with dysleXia to create a representation of their experience through art, either by themselves or as a collaborative project. Those between ten and sixteen years old were invited to workshops that specifically looked at language, using art as a starting point to understand how dysleXics expressed their experience with language. Those over sixteen years old were invited to create additional work about an aspect of dysleXia they wanted to represent. The resultant artworks were a way to ex- 
plore dysleXic everyday experiences, creating space for people to theorise and 'voice' their own experiences. My key collaborators also created group works, and when we held the installation for the work, they helped design interactive pieces for people who attended the exhibition.

Taussig (2011) argues that drawing creates particular ways of communicating about the body because the body must actively participate in the making of a drawing - the hand moves across the page. I would add that the process of making art creates new capacities for the body's knowledge to be expressed, and in the case of my research, even makes it possible to explore experiences that words are not able to express. For example, sensory experiences were often expressed through movement, colour and shape, and were sometimes accompanied by the phrase 'there are no words to explain this'. Art enabled embodied experiences to be expressed and to privilege the individual's knowing. The need for privileging embodied knowing was explained by Philippa, a seventeen-year-old dysleXic, as she made her artwork:

People don't realise that there is so much in here. They keep us compressed and won't let us stretch out. There is so much, even language in here, if they would just let us do what we need to do.

\section{ART OPENS SPACES}

Changing the focus from the mind/brain to the body (or as I called it in my research, 'embodied knowing', drawing on Rapport and Harris 2007 and Hogan and Pink 2010), meant that I needed to look at forms of communication and their potential for exploring experience. Altering practice to include artwork as exploration alters what can be communicated. As Sousanis (2015) suggests, altering perspective displaces existing frames of reference (Fig. 2).

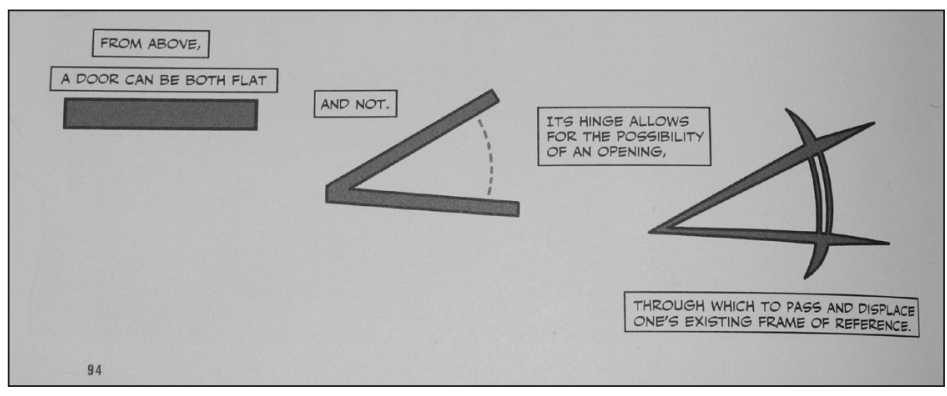

Figure 2. Sousanis 2015 p.94 
The 'hinge' that art provided in this research transformed the existing frame of the term 'dyslexia' into people's interpretations of their experiences of dysleXia. The works are not direct representations of a day in the life of a dysleXic person, but an interrogation of experience in the 'hinge [of] possibilities' (Sousanis 2015, 94), enabling an exploration and understanding of different ways of knowing the world.

Even though the artworks are not direct representations of a day in the life of a dysleXic, they draw on their embodied knowing. Merleau-Ponty (1945) suggested that Cezanne's art could not exist separate from his embodied experience of colour and light. Irving (2009) also found an affinity between expressions of experience through art and work created by people with HIV/AIDS who were close to death. Merleau-Ponty and Irving both see embodied experience interwoven with the creation of artworks. Similarly, the works created here could not exist without the knowledge and real-life experiences of the people who created them. Exploring experience through art showed complexities that were expressive of my collaborators' sensory cognition and of the realities of their lives, revealing vibrant, embodied knowing - and not simply the deficit theories that dominate the existing dyslexia literature.

\section{Working In Collaboration}

Participant observation, as the quote at the beginning of this article shows, was an active working together and involved my seeking to embody, as much as possible, their experiences. Working together meant trying to understand their perspectives, their sensory awareness of the world and their flexible use of language, which I found challenged my understanding of grammar and words and affects my writing process to this day. Participant observation as collaboration and my choice to describe those involved as 'collaborators' highlights our ongoing relationship and my responsibilities to the knowledge we created together. It represents my ethical responsibility to ensure their voices are heard and that the work remains accessible to the dysleXic community, as so much dyslexia research does not do this. Art, then, can be a method, an ethical decision and a way to communicate research. As I continue to write up my research, accessibility remains important, as I am still eager for my collaborators to access our work. Art makes this possible. Art became an ethnographic invitation to collaboratively explore experience and collaboratively represent different dysleXic voices. My collaborators chose different ways to represent their voices - from film, to digital art and sound, to sculpture.

Making art was not about creating pretty pictures. It involved complexities, 
including different creative processes and negotiating life experiences during the research period which affected their ability to work on the project. Craig was going through a struggle about his future, and this was reflected in our time together and the making of his work. He was always sure about what he wanted to create; every time we met to discuss what he would like to do and the tools he needed, he would present multiple new ideas. These included making a piece of jewellery and a sculpture that had images projected over it; all were projects he himself planned to make. Over the course of a year we continued to meet, and every time he was passionate about his ideas but could not progress from the idea to physical making. We continued meeting, and as time went by I became worried, so I suggested a possible way forward based on the discussions we had had. Each time we met Craig discussed the importance of eyes, talking about previous work he had made, how he read people and what was communicated through eyes. I suggested that these intersubjective relationships may be something to focus on and mocked up a possible design using metaphors he had used during our previous discussions. We then began working together on the piece, sometimes altering the metaphors or replacing them, altering the colouring or shapes of the image. Figure 3 represents our process, from my perspective, of collaborative making. The making of this image was part of a visual reflexive process on the method, an alternative to a written discussion as a way to meet my ethical objective of making the work accessible to dysleXics.

The initial mock up gave us a place to discuss what could be said about the experience he was representing, and what did not have words but had sounds, gestures, shapes or colours. I taught him how to make changes to the layers of the image using Photoshop, and as we sat in the café with the laptop open, he began to alter the images and describe whether they felt right to him. In creating the work, we theorised and explored his experience of the environment as a dysleXic. I do not believe that access to this information would have been achieved in the same way without the use of art, because Craig (like others) often went with something that 'felt right' to him rather than using words to express the reason for his choices. My many encounters with dysleXics describing the complexity of their sense perception of the world revealed aspects of dyslexic experience not previously documented in the literature, revealing their complex engagement with their sensory environment.

Art became a way to explore what it meant to be a dysleXic person, and for my collaborators it gave them a chance to share these with other dysleXics. The active engagement of art required that they: 


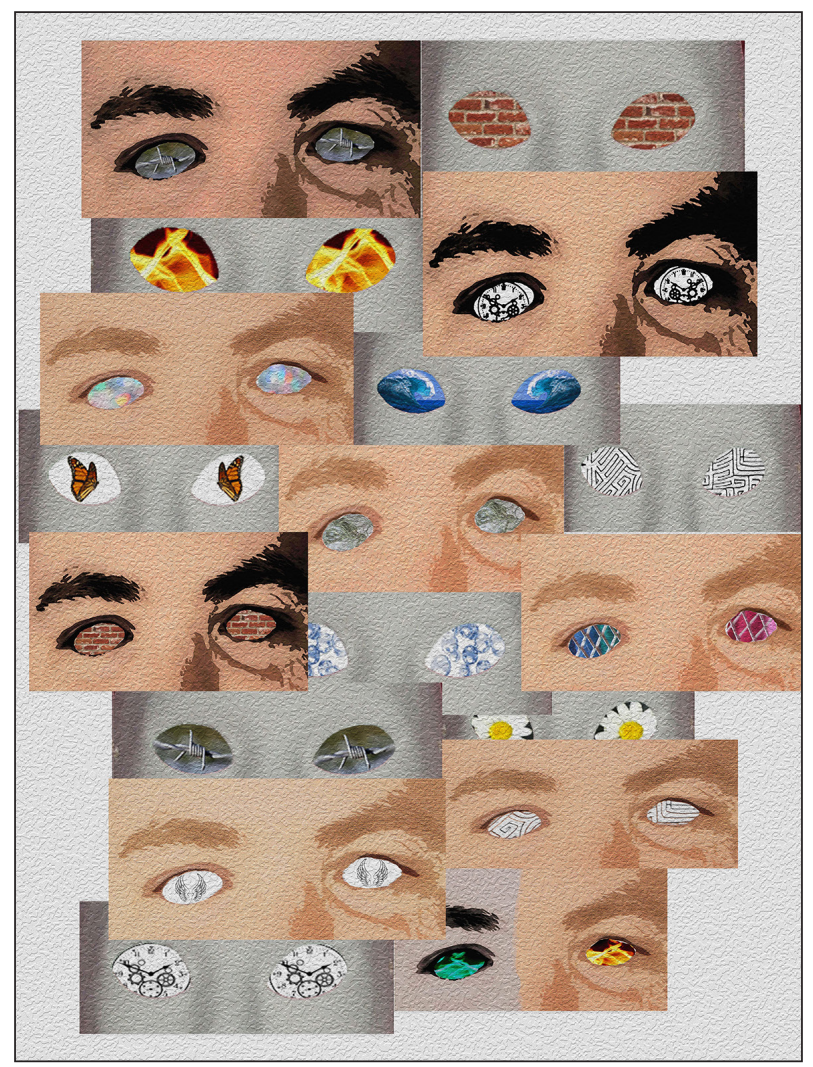

Figure 3. Visual exploration of fieldwork with Craig (Digital Collage).

gain enough distance from oneself to make oneself the object of one's ... gaze... . It is not simply to be a 'knower' in a way that this reflexive self-awareness can condition one's knowing, not only about the external world but also about oneself. (Smith 2010, 63)

In choosing this approach, my role as a collaborator involved the shared creation of artworks (when people wanted to create a particular representation but did not have the skills to do so we worked together), discussing the progress of the works, creating representations of key themes arising from the fieldwork and making group works with key collaborators. Of everyone who created art, only two people had previous training in drawing or other art forms, so there was little to no existing skill base. 
Through my own process of creating art and making art with my collaborators, I found art became a place for 'voicing' what had not or could not be said. For them, part of this 'making' included interacting with other dysleXics and finding shared experiences, as well as finding ways of communicating and expressing themselves in a collaborative project. Their embodied knowing became part of the exploration, alongside the various art mediums. An example of this is the exploration of sensory knowledge represented in figure 6, where the keys represent particles of the world gathered as they move through the world. As we finished the work sound was added to it, and it became interactive. As the keys were hung from sheer ribbons, they asked each other questions about whether the sound was right and whether it represented dysleXic 'flight'. Even though there is a lack of words in images like figure 6, they all contain complex information about lived experience and more specifically about sensory perception of the world.

\section{ART AS FIELDWORK AND ETHNOGRAPHY}

Words and artistic mediums, through the ways they draw on sensory embodied knowledge, are differently privileged expressions of bodies and experiences:

In the case of the visual $\operatorname{arts}^{7}$, their aesthetic distinctiveness flows out specifically from a privileged relation to human embodiment and its modes of visual perception and space occupancy. (Crowther 2009, 559)

Cox and Wright (2012) have also suggested that art mediums can evoke the life world', and through the act of making, have the potential to elicit communicative sensory experience by engaging the body as a whole in representation, as did the artworks created during my fieldwork. Pickering (2008) argues that the significance of experience can only be expressed through art due to its unique requirements. Here through the collaborative project, art actively engages with people's embodied knowing through their participation in expressing that world. Therefore, art opened a 'space' (Irving 2009, 295) in which to explore people's experiences and expressions of being-in-the-world.

As you will see, the images bring a different dynamic to the written, academic discourse about dyslexia. The use of an artistic method resulted in orchestrating the collaborators' everyday by representing the weaving of voices, sounds, images, silences, pauses, corporeality, sensory experience, and as Irving (2011) suggests, everyday processes, interiorities and formed and half-formed ideas (p.24). 
Layers of experience are communicated through the wearable art piece 'Education' (Figure 7), and part of the information communicated was the sensory corporeal knowing they gained in school. The artwork was expressive of different types of discomfort and pain, and in its making the aim was to give the viewer that physical experience as well. In figure 7 , where a cage sits over the head (representing a trapping of imaginative possibility and control of learning), they wished to illustrate the physical pressure and control they felt over their thinking and to give the viewer a similar sense of being trapped. Another important empathetic connection they wanted to make was through staring. Each of the key collaborators created eyes to attach to the cage. The number of eyes, their position, colour and look were central to the information they intended to communicate. The work was deemed to be finished when it felt 'right' (Elise), 'slightly creepy' (Craig) and 'judging' (Amanda).

Within visual anthropology, issues of representation through images remain controversial, due to questions about the analytical gap between visual and written academic theoretical work (Grimshaw and Ravetz 2005). However, in the moments of making these metaphors-of-knowing, theorising with the body, occupied the analytical gap. Using a collaborative approach meant that I had the privilege of participating in many explorations as my collaborators interacted with the making of the works and checked it against their own embodied knowing. Sensation, as an intersubjective space, became an important form of analysing experience and a way to communicate with others who did not share their knowledge.

\section{COMMUNICATING EXPERIENCE: METAPHORS-OF-KNOWING}

Ong (2002) suggested that due to the printed format written words appear to be consistent in how they communicate information. For example, 'are' can be written in different typefaces - are are are ARE are - but remains a plural verb when placed in a sentence, no matter the format of the text. In art, an object like a key, when altered, can become a metaphor for a multitude of different experiences as it does in figure 6. Lakoff and Johnson (2003) suggest that words are also metaphors drawn from embodied experience. They suggest that 'our conceptual system is largely metaphorical... what we think, what we experience, and what we do every day is very much a matter of metaphor' (p.1). However, what these different metaphors communicate, whether in art or words, and the expectations about the ways they communicate, affects both collaborative exploration and the communication of knowledge. My research revealed issues relating to different modes of representation, including words, shared experiences, body movements, sounds and artworks, all of which reflected the 
collaborators' complex relationships with words, corporeality and intersubjectivity. These 'complex relationships' mean that it is necessary to understand what words convey and the ways they are accessed within the dysleXic and collaborative context of this research. Ong (2002), a non-dyslexic, described words as predominantly linear products, where the page itself requires a particular type of interaction due to its margins, spacing and shape of letters, where the information unfolds through its reading. Barclay (2015), as a dysleXic, challenged this through dysleXic encounters with words 'Noe wun ever sed that reedeeng.... wuz eezee' (p.28). Perhaps in reading that quote you noticed differences in your embodied engagement with the text by alterations to your body position, altering the angle of your head, or perhaps holding your breath until you could understand the words. It required a different engagement with the spelling and pronunciation altering bodied practice. For dyslexics this bodied engagement with words is part of their everyday experience of text, resulting in words having additional information (such as that just experienced by reading the different spelling above) associated with them which may contradict the meaning of the word. Lakoff and Johnson (2003) suggest that words are bodied metaphors - here, these metaphors become more complex as other embodied experiences can dominate the ones the words are intended to communicate.

The body is a physical being and words can be either an abstraction of this embodied knowing or expressive of it as Barclay (2015) shows. Art is a different type of abstraction that can capture the movements of the body itself in a way that the typed form of this article cannot. How to access this information can be problematic because, unlike in reading and writing, we are not taught the way into the 'space occupancy' (Crowther 2009, 559) suggested earlier. Therefore words, whether written or spoken, create particular intersubjective spaces that impact the research field.

Wilder (2016), when discussing film that aims to create an empathetic response, describes the desire to create a connection with the audience as a 'configurational encounter' (p.126). A 'configurational encounter' does not necessarily have to be a recognised understanding of the work, as at times it can be a visceral response; 'Education' (Figure 7) was created to do this. In the intersubjective encounter the aim is a weaving of experience and expression into the work, even though the artist themselves may not be present.

In approaching collaborative sensory methodologies, it is important to consider the potential of communicative forms. The image, as Pink (2013) and Sousanis (2015) have suggested, provides potential. Van Heusden (2010) suggests that the different modality of art generates its ability to communicate life: 
Art does indeed represent the sensation of life, but it does not recover it, as it was never lost. Instead of representing life in terms of concepts and theories, it represents it mimetically by recreating the unfamiliar and confronting the recipient with an unstable reality. (van Heusden 2010, 161)

To explore this place of art a selection of the works created follows.
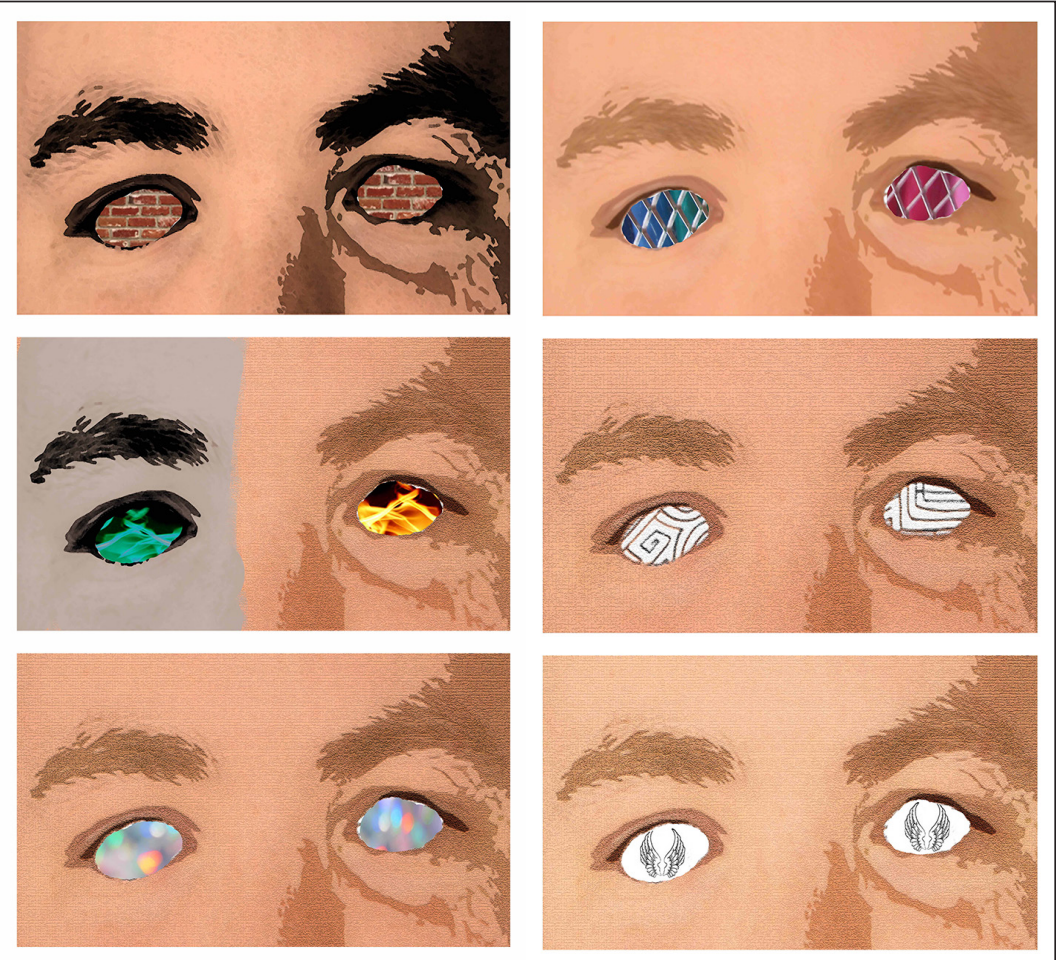

Figure 4. Looking in [digital collage, $2 \mathrm{~m} \times 1.75 \mathrm{~m}$, print]

\section{Looking in}

This collage was a collaboration between Craig and myself. Craig often talked about the information he knew about people, and would discuss this every time we met. As he spoke, he would use different metaphors that were later used and expanded on to represent his embodied experiences when looking at people: 
Just by body language and stuff like that, you kind of get a hint of what they are thinking and where the conversation's going to go. But there are those few that are that guarded that it's like a rebound. With a whole lot of new people it can be a little overwhelming but it fascinates me what I can tell about them, and freaks me out a bit, to be honest. (Craig)

Craig chose to use his own face and alter it to represent positive and negative experiences, choosing images and taking photographs of different objects that were used behind the eyes. Craig later described the $\operatorname{artwork}^{8}$ as more than just seeing, but a reading of the 'ness of and around people'.
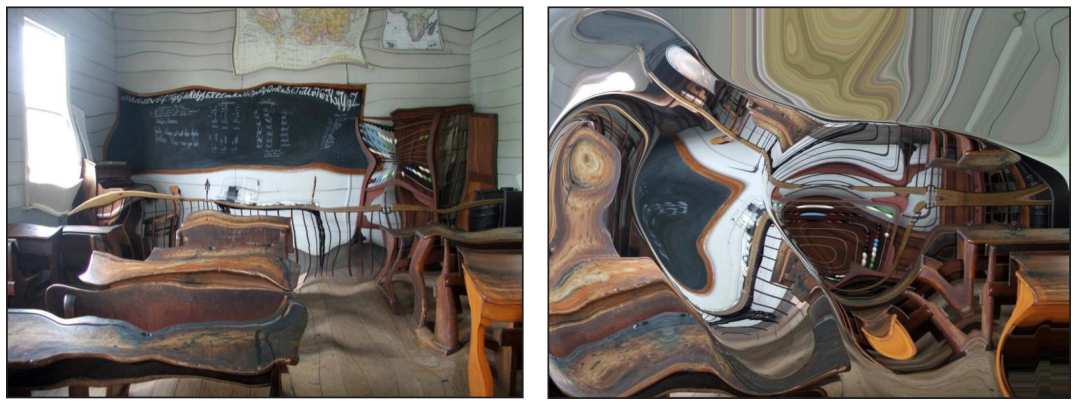

Figure 5. The room [two stills from a digital animation titled 'When I walk into a room...']

\section{The Room}

'The Room' stills are taken from an animated film made to explore and represent how paying attention to the world in a different way can also be an overwhelming experience.

Thinking about rooms I've walked into, classrooms, there's a hang of a lot of information, so you focus on one thing to get it under control, and then you can sit down and work it out. I prefer to sit and work it out, than stand and work it out. You focus on one point; maybe a blackboard or where you're sitting. My body buzzes and therefore to sit down gives it more control. Yeah, it's about control, and in a learning environment you have to control it fast. (Elise)

The short that the stills above are taken from seeks to communicate embodied 
knowing through a sensory engagement triggered through sight/touch. Elise's children, who are also dysleXic, helped to create different parts of the stopmotion animation using Photoshop to alter the original image. The animation was created using a single photograph we took together, and focuses on mimetic interaction of experience. The sense of dizziness and 'off-balance' feeling created in the clip is part of the communicative spaces used in the film to develop a mimetic engagement with the individual's experience.
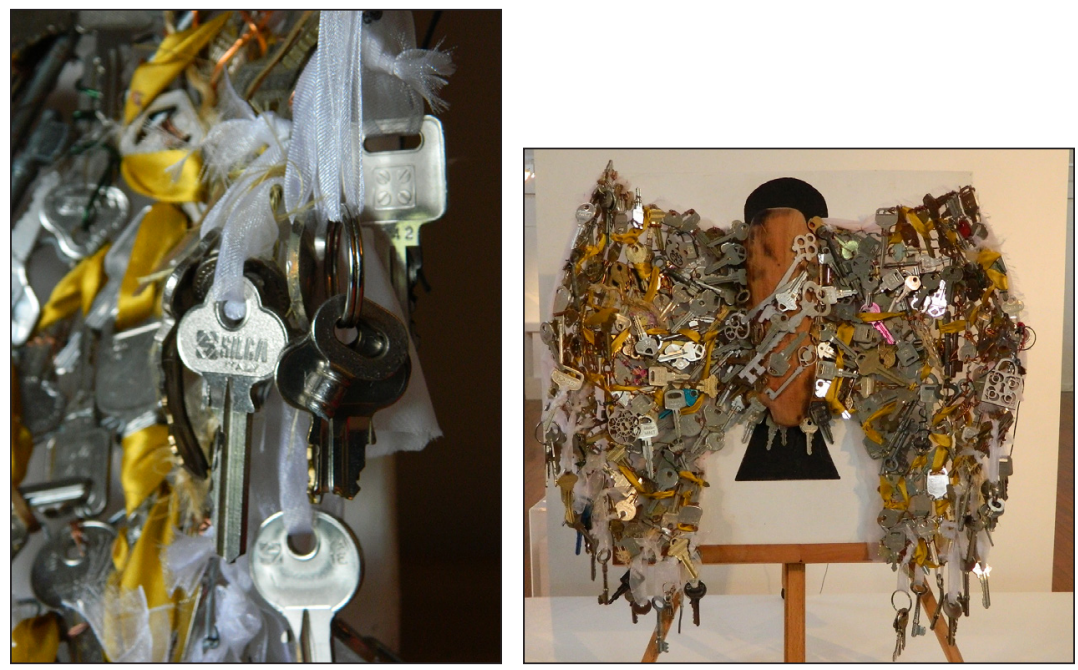

Figure 6. Attaining [recycled keys, wire, wood, ribbon. $50 \mathrm{~cm} \times 56 \mathrm{~cm}$ ]

\section{Attaining}

My collaborators all have different ways of negotiating their daily lives. The keys initially represented this adaptation. After the creation of the word 'ness', this artwork took on additional meaning and became associated with ness, which I discuss shortly. The wings were described in a variety of ways by my collaborators - as being like butterfly wings that collect particles of the world as they fly, or relating it to their own experiences of gathering sensory-cognitive information. The keys represent the accumulation of thoughts, memories, knowledge, images, senses, possibilities and skills over a life's journey. The journey is not silent and during the workshop, in order to finish the piece, sound was added. To represent this, keys were attached by ribbons. My collaborators took time and checked with each other to find the right sound to represent the wings in flight. 

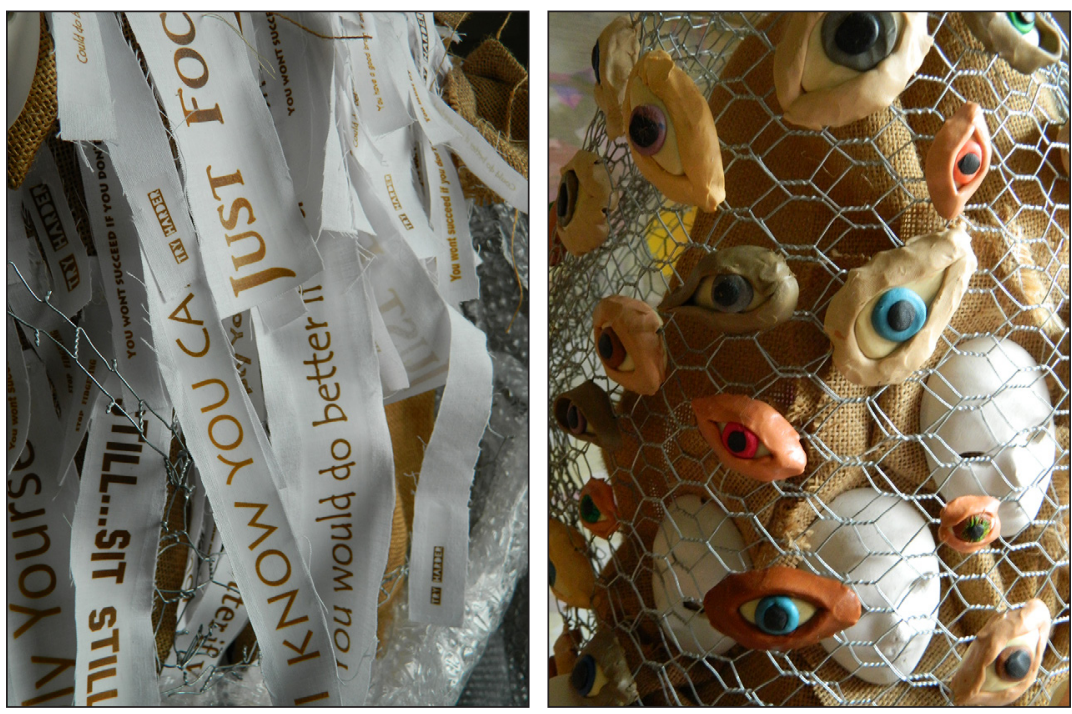

Figure 7. Education $[1 \mathrm{~m} \times 0.57 \mathrm{~m}$ tall, hessian cloak with plasticine, fabric, paint, wire, rope, rocks]

\section{Education}

This is a full-size cloak made with my key collaborators. The work represents experiences of education, using strips of words with comments from their report cards and the staring eyes of classmates and teachers. The cloak has multiple metaphors of dysleXic experiences, a central experience being the inability to learn in a way that used their sensory perception and embodied cognition.

I began this piece to interact with the information I had been told during my interviews, and I invited people to comment on them, add to them or disagree with them. It was a piece where I started to 'write up' my collaborators' experiences and was then directed to make changes, finally finishing with a workshop where we completed the piece together. There were discussions about whether it should be wearable art, to give it an embodied experience and add information that may not translate from just looking at it. As the work progressed, the importance of being restrained became more important than the wearing of the work, and it was displayed on a torso. 

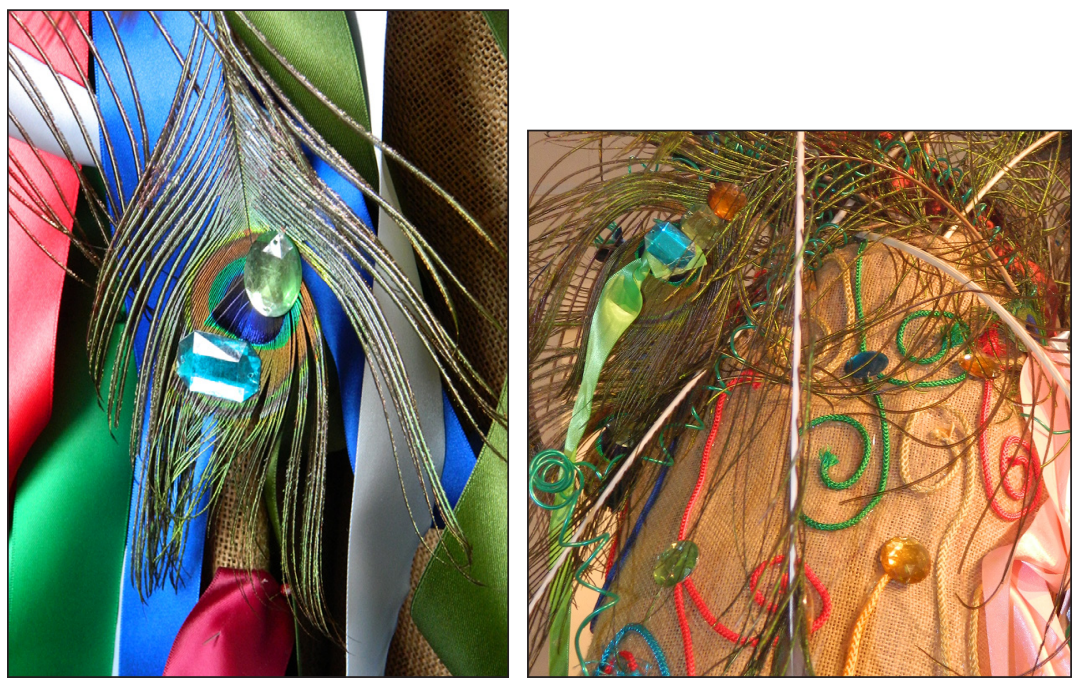

Figure 8. Learning [2.2 $\mathrm{m}$ high, hessian, ribbon, paint, feathers, wire, cord, plastic gems]

\section{Learning}

Learning is the juxtaposition of the education cloak, and sits alongside it. Where Education keeps to set uniform colours and is bound up, Learning explodes with colour in every direction, showing the expansiveness of possibilities and value of knowledge. As with the previous piece, I received feedback from my collaborators on changes that needed to be made. This included making the work go 'up and out', rather than being contained. The cloak was completed at the workshop where my key collaborators worked, adding movement to the cloak using feathers, ribbons and wire. Different parts of the cloak represent engagement with sensory knowing and embodied experience as spiralling thought patterns, achievement, movement expressing possibilities and colours playing off of each other adding communication of the potential connections learning can create.

\section{On reflection}

'On reflection' represents the different ways in which my collaborators see and interact with everyday sensory awareness in their life-world. The mirrors that run across the surface of the body alter perspectives on objects reflected in their surfaces to represent different ways of seeing the world. The piece represents sensory experience and recognition of the world as multi-dimensional and 

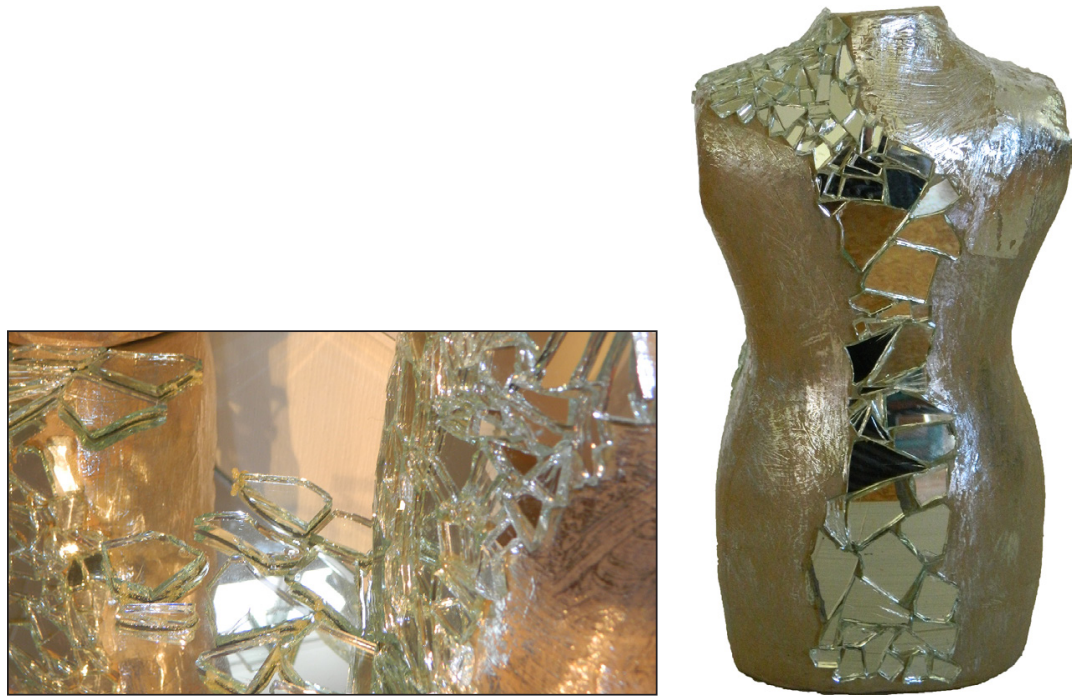

Figure 9. On reflection $[56 \mathrm{~cm} \times 1200 \mathrm{~cm}$, cardboard, silver leaf, mirrors]

linked to body sensation. To reinforce this connection, the back of the torso has mirrors running up and down the spine. In the gallery, the original artwork included mirrors on and around the torsos to represent reflection towards the body as well as away from the body towards the world.

COMMUNICATING EXPERIENCE: METAPHORS-OF-KNOWING CONTINUED

The 'mimetic representation' (van Heusden 2015) of experience, as the work above shows, can create instability as an audience may struggle to make sense of it. Through 'making strange' the everyday (what Shklovsky 1917 calls ostranenie) the works ask for time by asking viewers to look further for meaning.

The technique of art ... to make objects "unfamiliar", to make forms difficult, to increase the difficulty and length of perception because the process of perception is an aesthetic end in itself and must be prolonged. (Shklovsky 1917, 2)

In anthropology, the aim of making the strange familiar, and the familiar strange, takes on a different perspective. Making strange encourages perception and questioning of the artworks. Paskow (2004) suggests that this perception and interpretation of art is layered, involving three stages: 
1. The initial seeing of the work and the viewer's immediate response to it.

2. The viewer trying to understand what the artist was trying to say.

3. Seeking understanding through understanding the mediums used. (p.175)

These different stages of interaction and interrogation expose the potential of exploring meaning through art, providing what I call empathic moments (Gibbons 2016). Harnessing Paskow's (2004) interaction through 'making ostranenie' (Shklovsky 1917), my collaborators actively used layers of interaction for the audience within their work and in their process of making as well. The method, materials, purpose and experience were part of this communication of knowing. Both Paskow (2004) and Shklovsky (1917) describe art as involving theoretical and methodological work, which the collaborative process here shows happens in both their creation and in the audience's interaction. The artworks as metaphors-of-knowing directly engage with dysleXic experience, whilst at the same time offering other modes of thinking and engagement using art as a 'map into the living landscape to which it relates' (Pickering 2008, 24).

Metaphors-of-knowing in words and images impact on intersubjective encounters and a collaborative space; as a way of adding more information, often through communicating sensory knowledge. However the way metaphor is used and the ways in which words have hierarchical place (particularly within academia), visual metaphors, whilst communicating experience, are not regarded as representationally sufficient. Due to the academic context of my research, words were also important. I found that when I came to write up my research, I struggled to do so, as many of the experiences did not have words to represent them and my collaborators themselves had not used words to express them. By this, I mean that when I tried to write up the experiences expressed in the artworks, often words were missing as no word existed that summed up the knowing. In part I could do this reflexive process by using sensory exploration through my own arts practice, using Photoshop, AfterEffects, film and sound. However, in the context of a $\mathrm{PhD}$, this visual approach is not regarded as a sufficient analysis, as words predominate in the communication of and discussion about research, as epitomised in the word count required of a $\mathrm{PhD}$ thesis.

Therefore, new ways of discussing knowledge of words, paying attention to sensory information and moving through the world needed words, but these did not yet exist as the experiences came out of the ethnographic process and were therefore not part of the existing discourse on dyslexia. I needed to address this issue, as an academic thesis requires words. I told my key collaborators 
of my struggle with writing about their experiences and concerns; that I was missing the words to express their stories and needed their help. Over a meal, with lots of laughter, people jumping up and down from the table, scribbling notes, gestures and drawing, we tried to formulate letters into words, attempting to grasp together something that could hold so much meaning. We created a total of six new words to express the experiences that they explored in the artworks. One of these new words represents the experience and expression of dysleXic sensory paying attention to the world: 'ness'. Ness represents the multisensory weaving of information gathered across a person's sensory landscape and represents the experience and expression of navigating everyday life from a dysleXic perspective. Ness, which was first explored in the artworks, is about the 'more' of the world; the unseen experiences, ideas, possibilities and hidden flows of information. The artworks express ness as being part of intersubjective spaces and sensory landscapes, enabling a layering of this information through different artistic forms. The word itself doesn't show these complexities; it has four letters and is, as Lakoff and Johnson (2003) suggest, a metaphor containing experiences, knowledge, knowing and history, but it is missing the embodied expression through movement, gesture and sound which art provides.

\section{CONCLUSION}

In this article I have discussed the embodied knowings of people with dysleXia, using artworks created during fieldwork that was later called 'ness'. In doing so, I have focused on how a collaborative practice brings different approaches to fieldwork and also opens the field to other types of knowledge gathering. In doing so I have highlighted the use of art as a collaborative space and discussed how life influences the making of art in the field. As can be seen in the artwork shown, the different physical, created elements overlap with meaning and experiences by using the artistic forms as a place to represent metaphorsof-knowing. The images here are static, but were made by knowing persons through embodied movement, giving a unique representation of the body as communicator. Therefore, the artworks, whilst presented in this article as static images, can also be considered through their active making. Shapiro (2014) suggests this is through embodied cognition, but I would add it is also through embodied knowing gained through their corporeal reality. The artworks gave a place for the expression of embodied knowing, and resulted in a sensory dialogue with the making of the works. The complex realities of people with lived experiences of dyslexia explored through art revealed the corporeality and embodied metaphors of dysleXic experience. The artworks created were not simply pictures or sculptures to represent people's experiences, but a considered product made to stand for them expressing embodied experience. They 
represent people reflecting and theorising about themselves through embodied interaction with art.

NOTES

1 Ruth Gibbons received a PhD in Social Anthropology from Massey University in 2016. She is interested in interior dialogue, memory, imagination, bodily perception and silences by means of visual, sensory and bodily perception within her collaborative practice. Her work centres around a multi-layered multi-media approach to research through the use of experimental research methods. Her practice focuses around embodied knowing using a multi-media approach including digital animation, sculpture, soundscapes, experimental film and digital collage. Ruth currently teaches courses in anthropology and the BA core at Massey University, Auckland. Her current research continues in the area of dyslexia and is looking at the use of HoloLenses (a mixed-reality technology) as a research method and as a tool for the representation of research.

Email: R.Gibbons@massey.ac.nz

2 The restrictions on access to academic research has been challenged by growing discussion in the public domain (Stoller 2017).

3 I use this term deliberately, drawing on the work of Smith (2010) who explores the concept of personhood as an active being rather than a subject to be researched.

4 The proportion of dyslexics in NZ is suggested to be one in seven although some studies in other parts of the world have found rates closer to one in five. These rates are influenced by who is able to afford a diagnosis as it can be expensive.

5 To date, no treatment has proven to be effective for dyslexia. A diagnosis results in a label but doesn't necessarily lead to effective treatment. I have spoken with many parents about the relief they felt after diagnosis because they believed they could now fix the issues; they quickly discovered that this was not the case. Instead, they found themselves facing a minefield of information and misinformation by well-intentioned people who wanted to help.

6 For further discussion of my use of 'the aesthetic', see Gibbons (2016).

7 To this I would add all artworks including sound.

8 As part of this project we also created new words to represent the experiences we found. A brief discussion of ness appears later in this article. 


\section{REFERENCES}

Barclay, Sam. 2015. I Wonder What it's Like to be Dyslexic. Great Britain: PushPrint.

Bishop, Dorothy V.M. 2007. 'Curing Dyslexia and Attention-Deficit Hyperactivity Disorder by Training Motor Co-Ordination: Miracle or Myth' Journal of Paediatrics and Child Health 43 (10): 653-655.

Braun, Eldon M., and Ronald D. Davis. 2010. The Gift of Dyslexia, Revised and Expanded: Why Some of the Smartest People Can't Read... and How They Can Learn. New York: Penguin.

Buck-Morss, Susan. 1992. 'Aesthetics and Anaesthetics: Walter Benjamin's Artwork Essay Reconsidered'. October 62:3-41.

Caroll, Julia M., and Jane E. Iles. 2006.'An Assessment of Anxiety Levels in Dyslexic Students in Higher Education'. British Journal of Educational Psychology, 76: 651-662.

Chevin, Gary. 2009. Dyslexia: Visually Deaf? Auditory Blind? Bloomington: Author House.

Cox, Rupert, and Christopher Wright. 2012. 'Blurred Visions: Reflecting Visual Anthropology' in The SAGE Handbook of Social Anthropology, edited by Richard Fardon, Olivia Harris, Trevor H.J. Marchand, Mark Nuttall, Cris Shore, Veronica Strang and Richard A Wilson. London and Thousand Oaks: SAGE, pp.116-129.

Crowther, Paul. 2009. Phenomenology of the Visual Arts (Even the Frame). Stanford: Stanford University Press.

Dehaene, Stanislas, Felipe Pegado, Lucia W. Braga, Paulo Ventura, Gilberto Nunes Filho, Antoinette Jobert, Ghislaine Dehaene-Lambertz, Régine Kolinsky, José Morais, and Laurent Cohen. 2010. 'How Learning to Read Changes the Cortical Networks for Vision and Language'. Science 330 (December):1359-1364.

Nicholson, Tom, and Susan Dymock. 2012. The New Zealand Dyslexia Handbook. Wellington: NzCER Press.

Edwards, Jeanette, Penelope Harvey, and Peter Wade. 2010. Technologized Images, Technologized Bodies. New York and Oxford: Berghahn Books. 
Eide, Fernette. 2016. 'Dyslexic Advantage'. Accessed July 2018 from http://www. dyslexicadvantage.org/critical-review-of-the-use-of-strattera-on-healthychildren-with-dyslexia/

Eide, Brock L., and Fernette Eide. 2011. The Dyslexic Advantage: Unlocking the Hidden Potential of the Dyslexic Brain. New York: Hudson Street Press.

Elliott, Julian, and Elena Grigorenko. 2014. The Dyslexia Debate. New York: Cambridge University Press.

Gardner, Sally. in Varvardies, Lennie. (Creative Producer) and Kazimir Bielecki (Creative Director). 2012. Dysplamentary [Video File]. London: DYSPLA.

Gibbons, Ruth. 2016. "It's all of these puzzle pieces": The representation and the manifest discourse of dyslexic experience. $\mathrm{PhD}$ thesis, Massey University (Auckland).

Grimshaw, Anna, and Amanda Ravetz. (2005). Visualizing Anthropology. Bristol: Intellect Books

Hogan, Susan, and Sarah Pink. 2010. 'Routes to Interiorities: Art Therapy and Knowing in Anthropology'. Visual Anthropology 23 (2):158-174

Ingold, Tim. 2013. Making: Anthropology, Archaeology, Art and Architecture. London and New York: Routledge.

Irving, Andrew. 2009. 'The Colour of Pain'. Public Culture 21 (2):293-391.

Irving, Andrew. 2011. 'Strange Distance: Towards an Anthropology of Interior Dialogue'. Medical Anthropology Quarterly 25 (1):22-44.

Koenig, Olivier, Stephen M. Kosslyn, and Peter Wolff. 1991. 'Mental Imagery and Dyslexia: A Deficit in Processing Multipart Visual Objects?' Brain and Language 41(3):381-394.

Lakoff, George, and Mark Johnson. 2003. Metaphors We Live By. Chicago and London: University of Chicago Press.

Merleau-Ponty, Maurice. 1964 [1945]. 'Cezanne's Doubt'. In Sense and Non-Sense, Evanston: Northwestern University Press, pp.9-25. 
Ong, Walter J. 2002. Orality and Literacy 3oth Anniversary Edition. Abingdon and New York: Routledge.

Paskow, Alan. 2004. The Paradoxes of Art: A Phenomenological Investigation. Cambridge: Cambridge University Press.

Pickering, Michael. 2008. Research Methods for Cultural Studies. Edinburgh: Edinburgh University Press.

Pink, Sarah. 2013. Doing Visual Ethnography. London and Thousand Oaks: SAGE.

Price, Cathy J., D. Howard, K. Patterson, E.A. Warburton, K.J. Friston, and R.S.J. Frackowiak. 1998. 'A Functional Neuroimaging description of Two Deep Dyslexic Patients. Journal of Cognitive Neuroscienc 10 (3):303-315.

Raphael, Dana, Mike Salovesh, and Martha Laclave. 2001. 'The World in 3D: Dyslexia, Dysgraphia, Dysnumia'. Disability Studies Quarterly 21 (3):152-160.

Rapport, Nigel J. 2007. 'A Discussion Concerning Ways of Knowing'. In Ways of Knowing, edited by Mark Harris. New York and Oxford: Berghahn Books, pp.306-330.

Rosen, Glenn D., ed. 2006. The Dyslexic Brain: New Pathways in Neuroscience Discovery. Mahwah, NJ: Lawrence Erlbaum Associates.

Rowan, Linda M. 2010. 'It's Not All Black and White: The Transition of Students with Dyslexia into the First Year of University'. Master's thesis, Massey University (Manawatu).

Shapiro, Lawrence. 2014. The Routledge Handbook of Embodied Cognition. Abingdon and New York: Routledge.

Shaywitz, Sally. 2008. Overcoming Dyslexia: A New and Complete Science-Based Programme for Reading Problems at any Level. New York: Random House.

Shaywitz, S., Bennett Shaywitz, Linda Wietecha, Sharon Wigal, Keith McBurnett, David Williams, William G. Kroenberger, Stephen R. Hooper. 2015. 'Effect of Atomoxetine Treatment on Reading and Phonological Skills in Children with Dyslexia or Attention-Deficit/Hyperactivity Disorder and Comorbid Dyslexia in a Randomized, Placebo-Controlled Trial. Journal of Child and Adolescent Psychopharmacology 20 (20):19-28. 
Shkovsky, Viktor. 1917. 'Art as Technique'. Accessed 1 July 2018 from https://paradise. caltech.edu/ist4/lectures/Viktor_Sklovski_Art_as_Technique.pdf

Siok, Wai Ting, Zhendong Niu, Zhen Jin, Charles A. Perfetti, and Li Hai Tan. 2008. 'A Structural-Functional Basis For Dyslexia in The Cortex of Chinese Readers'. Proceedings of the National Academy of Sciences 105 (14):5561-5566.

Smith, Christian. 2010. What Is A Person? Rethinking Humanity, Social Life, and the Moral Good from the Person Up. Chicago: University of Chicago Press.

Smythe, Ian, John Everatt, and Robin Salter. 2004. International Book of Dyslexia: A Guide to Practice and Resources. Chichester: John Wiley and Sons Ltd.

Sousanis, Nick. 2015. Unflattening. Cambridge, MA and London: Harvard University Press.

Stoller, Paul. 2017. 'Engaging Public Anthropology'. Anthropology Matters 17 (1) https://www.anthropologymatters.com/index.php/anth_matters/article/ view/473/606.

Taussig, Michael. 2011. I Swear I Saw This: Drawings in Fieldwork Notebooks, Namely My Own. Chicago: University of Chicago Press.

van Heusden, Barend P. 2010. 'Estrangement and the Representation of Life in Art'. In Ostrannenie: On 'Strangeness' and the Moving Image. The History, Reception, and Relevance of a Concept, edited by Annie van den Oever, 157-164. Amsterdam: University of Amsterdam.

Vidal, Fernando, and Francisco Ortega. 2017. Being Brains: Making the Cerebral Subject. New York: Fordham University Press.

Wilder, Ken. 2016. 'Projective art and the "staging" of empathic projection'. Moving Image Review and Art Journal 5 (1/2):124-140. 